Article

\title{
Electro-Conductive Composite Gold-Polyethersulfone-Ultrafiltration-Membrane: Characterization of Membrane and Natural Organic Matter (NOM) Filtration Performance at Different In-Situ Applied Surface Potentials
}

\author{
Tomi Mantel * (D), Paul Benne, Stanislav Parsin and Mathias Ernst ${ }^{(\mathbb{D})}$ \\ Institute for Water Resources and Water Supply, Hamburg University of Technology, \\ Am Schwarzenberg-Campus 3, 20173 Hamburg, Germany; paul.benne@tuhh.de (P.B.); \\ stanislav.parsin@tuhh.de (S.P.); mathias.ernst@tuhh.de (M.E.) \\ * Correspondence: tomi.mantel@tuhh.de; Tel.: +49-40-4287-83920
}

Received: 28 June 2018; Accepted: 7 August 2018; Published: 16 August 2018

\begin{abstract}
Next to the pore size distribution, surface charge is considered to be one main factor in the separation performance of ultrafiltration (UF) membranes. By applying an external surface potential onto an electro-conductive UF membrane, electrostatic induced rejection was investigated. This study introduces in a first part a relatively simple but yet not reported technology of membrane modification with direct current sputter deposition of ultrathin $(15 \mathrm{~nm})$ highly conductive gold layers. In a second part, characterization of the gold-coated UF flat sheet membrane with a molecular weight cut-off (MWCO) of $150 \mathrm{kDa}$ is presented. Membrane parameters as contact angle (hydrophobicity), pure water permeability, MWCO, scanning electron microscopy imaging, zeta potential, surface conductivity and cyclic voltammetry of the virgin and the modified membrane are compared. Due to the coating, a high surface conductivity of $10^{7} \mathrm{~S} \mathrm{~m}^{-1}$ was realized. Permeability of the modified membrane decreased by $40 \%$ but MWCO and contact angle remained almost unchanged. In a third part, cross-flow filtration experiments with negative charged Suwannee River Natural Organic Matter (SRNOM) are conducted at different cathodic and anodic applied potentials, different $\mathrm{pH}$ values ( $\mathrm{pH} 4,7,10)$ and ionic strengths $\left(0,1,10 \mathrm{mmol} \mathrm{L}^{-1}\right)$. SRNOM rejection of not externally charged membrane was $28 \%$ in cross-flow and $5 \%$ in dead-end mode. Externally negative charged membrane $(-1.5 \mathrm{~V}$ vs. $\mathrm{Ag} / \mathrm{AgCl})$ reached rejection of $64 \%$ which was close to the performance of commercial UF membrane with MWCO of $5 \mathrm{kDa}$. High ionic strengths or low $\mathrm{pH}$ of feed reduced the effect of electrostatic rejection.
\end{abstract}

Keywords: electro-conductive membrane; electro-enhanced rejection; surface charge; membrane characterization; electro-ultrafiltration; surface coating

\section{Introduction}

Ultrafiltration (UF) is an established technology for water treatment due to its high permeability at sufficient rejection rates for turbidity and pathogens as well as its relatively compact footprint $[1,2]$. Especially if it comes to tight UF, rejection mechanisms are not entirely understood, because rejection rates cannot simply be explained by size exclusion effects [3]. Next to the nominal pore size and pore size distribution of a UF membrane, surface charge is considered to be a relevant factor in influencing separation performance of UF membranes [4]. Several studies have been published about the influence of the membranes surface zeta potential on fouling and rejection behavior of UF 
membranes. Accordingly, negative membrane charge (identified by measured negative zeta potential) is considered to result in higher rejection rates for negatively charged substances such as natural organic matter (NOM). Moreover, lower fouling rates have been reported under such surface charge conditions $[5,6]$.

By the utilization of an electrically conductive UF membrane, external in-situ charging of membrane becomes possible during filtration without changing of any other membrane properties. Using this novel approach, the impact of membrane surface potential on filtration performance can be evaluated for different applied cathodic and anodic potentials; furthermore, the membrane surface potential can be changed during a running experiment which leads to new experimental opportunities to study the impact of surface charge.

In the past five years, research on electrically conductive membranes (ECM) increased considerably. ECMs have been proposed and investigated for rejection enhancement as well as fouling control. Several research groups showed the application of novel developed ECMs for water treatment in the context of fouling mitigation and scaling inhibition [7-9].

For this study, an electro-conductive UF membrane was prepared by sputter coating of a commercial polymer UF flat sheet membrane. Sputter deposition is a widespread and economic method to create ultrathin conducting layers for scientific (e.g., scanning electron microscopy (SEM) imaging) or industrial (e.g., thin films) application [10]. DC sputtering of gold proved to be a simple and consistent method to create an ultrathin conducting layer on the membrane surface. Sputter coating of membranes with different metals as palladium or platinum were reported by a few studies; however, such membranes were used for hydrogen gas separation [11] or the coating was primarily for analytical purpose (e.g., in-situ analyses of fouling of UF membrane by measuring double layer potential [12,13]). Accordingly, no external electrostatic potential was applied to conductive metal-polymer-composite membranes during water filtration experiments so far.

The present study focuses on the investigation of the electrostatically induced rejection mechanisms by the external control of cathodic and anodic surface potentials; the filtration experiments are conducted with negative charged NOMs as model foulants, which are typically found in natural water resources. Moreover, impact of water matrix (ionic strength) and $\mathrm{pH}$ are investigated with respect to the electrostatically enhanced rejection mechanism. By this, a possible functionalization of the membrane performance with external in-situ charging is targeted.

\section{Materials and Methods}

\subsection{Preparation of Gold-Polymer-Composite Membrane}

Polyethersulfone (PES) UF flat sheet membrane UP150 with a molecular weight cutoff (MWCO) of $150 \mathrm{kDa}$ and nominal pore size of $26 \mathrm{~nm}$ was applied (Microdyn-Nadir GmbH, Wiesbaden, Germany). The membrane was cut into rectangular sheets $(100 \mathrm{~mm} \times 50 \mathrm{~mm})$ and then coated without any previous treatment with a direct current sputter coater on the active layer with gold (Sputter Coater SCD 005, Baltec Inc., Balzers, Lichtenstein). Sputter deposition was carried out in intervals of $5 \mathrm{~nm}$ gold layer thickness and then stopped for $10 \mathrm{~s}$. This procedure was repeated for three times to accomplish a final gold layer thickness of $15 \mathrm{~nm}$. The duration for the complete coating of $15 \mathrm{~nm}$ gold was approximately 180 seconds. The growth rate of the gold layer on the membrane surface was determined with a quartz micro balance (EM QSG100, Leica, Germany) and was approximately $0.1 \mathrm{~nm} \mathrm{~s}^{-1}$. DC sputter current was set at $40 \mathrm{~mA}$, sputter voltage was 400-500 V, working pressure was $5 \mathrm{~Pa}$, working distance was $50 \mathrm{~mm}$ and the operating gas was argon. After the coating process, the membranes were rinsed in purified water (Milli-Q, Millipore Corporation, Billerica, MA, USA) for at least $24 \mathrm{~h}$. Prior to experiments, membranes were washed by filtration of at least $1 \mathrm{~L}$ of pure water. 


\subsection{Membrane Characterization}

\subsubsection{Pure Water Permeability}

Pure water permeability was measured for each membrane before every experiment at a transmembrane pressure (TMP) of 1 bar and a cross-flow velocity of $0.16 \mathrm{~m} \mathrm{~s}^{-1}$ (three virgin membranes and three Au-coated membranes with 5, 10 and $15 \mathrm{~nm}$ ). Calculation followed Equation (1) with $\dot{V}$ as permeate volume flow, $A$ as membrane area and $p$ as pressure.

$$
P=\frac{\dot{V}}{A p t}\left[\frac{L}{m^{2} b a r h}\right]
$$

\subsubsection{Hydrophobicity-Contact Angle}

Contact angle was measured by captive bubble method [14] with a self-assembled microscope setup. Experiments were conducted 12 times (or more) with random pieces from virgin membranes and $15 \mathrm{~nm}$ gold coated membranes. The dimensions of the membrane pieces were $20 \mathrm{~mm} \times 30 \mathrm{~mm}$. For graphical evaluation of the contact angle, the software Surftens (OEG GmbH, Frankfurt an der Oder, Germany) was used. Additional information is supplied in supplementary material.

\subsubsection{Scanning Electron Microscopy}

Scanning electron microscopy (SEM) imaging was conducted at the electron microscopy unit (BEEM) of Hamburg University of Technology with Zeiss Leo Gemini 1530 (Carl Zeiss AG, Oberkochen, Germany). Before microscopy, virgin membranes where coated with $1.5 \mathrm{~nm}$ of gold to create contrast for SEM imaging (Sputter Coater SCD 005). Conductive membranes were not coated any further. The acceleration voltage was $2.0 \mathrm{kV}$.

\subsubsection{Zeta Potential}

Zeta potential of virgin and coated membrane was investigated with Surpass (Anton Paar GmbH, Graz, Austria) at $1 \mathrm{~mol} \mathrm{~L}^{-1} \mathrm{KCl}$. Measurement started at $\mathrm{pH} 9$ and through titration of $\mathrm{HCl}$, the $\mathrm{pH}$ was decreased until $\mathrm{pH}$ 3. Membranes were cut into the dimensions of gap cell $(20 \mathrm{~mm} \times 10 \mathrm{~mm})$ and stored in pure water for $24 \mathrm{~h}$ before the measurement. Zeta potential was calculated according to the streaming potential method by Helmholtz-Smoluchowski equation with the Software Attract supplied by the manufacturer of Surpass [15]. For more detailed information, the following reference is recommended [16].

\subsubsection{Molecular Weight Cut-Off}

For MWCO determination of the coated and uncoated membrane, polyethylene glycol (PEG) standards were used with molecular weights of 12.3, 26.1, 42.7, 98 and $200 \mathrm{~g} \mathrm{~mol}^{-1}$ (or kDa) and one dextran standard with 130 kDa (PSS Polymer Standards Service GmbH, Mainz, Germany). Rejection is calculated according to Equation (2). In order to avoid concentration polarization effects, permeate samples were taken after $20 \mathrm{~mL}$ of filtration. Experiments were done in stirred dead-end cells (Amicon Model 8200, Millipore Corp., Billerica, MA, USA) with a volume of $200 \mathrm{~mL}$, active membrane surface area of $28.7 \mathrm{~cm}^{2}$, TMP of 1 bar and stirring speed of $300 \mathrm{rpm}$. Concentration of feed solution was set to $20 \mathrm{mg} \mathrm{L}^{-1}$. Measurement of PEGs and dextran concentration was conducted via the total organic carbon (TOC) detection of TOC-Analyzer (TOC Shimadzu, TOC-L CPH, Kyoto, Japan). Prior to the MWCO experiments, $1 \mathrm{~L}$ of pure water was filtered through the membrane to clean them.

$$
R=\left(1-\frac{c_{\text {Permeate }}}{c_{\text {Feed }}}\right) \cdot 100 \%
$$




\subsubsection{Electrical Properties of Conductive Membrane Electrode}

The electrical conductivity of the membrane was measured following the Van der Pauw method (four-point method) [17]. At least three random membrane pieces of each membrane (respectively gold layer thickness 5,10 and $15 \mathrm{~nm}$ ) were chosen and measured for at least ten times.

Cyclic voltammetry (CV) was carried out using a three-electrode system with $\mathrm{Ag} / \mathrm{AgCl}$ electrode (Xylem Analytics GmbH, Meinsberg, Germany) as reference electrode and coated active layer of membrane as working electrode and stainless steel sheet as counter electrode. The electrode area was $42 \mathrm{~cm}^{2}$. For the setup of parameters for cyclic voltammetry, EcmWin-Software (IPS Elektroniklabor $\mathrm{GmbH}$, Münster, Germany) was used. The CV scan rate was $100 \mathrm{mV} \mathrm{s}^{-1}$ over a potential range of -4.0 to $+4.0 \mathrm{~V}$ vs. $\mathrm{Ag} / \mathrm{AgCl}$. Measurements were conducted with Suwannee River Natural Organic Matter (SRNOM) solution (see Section 2.3.2) at sodium chloride concentrations of $0.1,1$ and $10 \mathrm{mmol}$ $\mathrm{L}^{-1}$. The scan started at $0 \mathrm{~V}$ in the positive direction and was executed for 3 cycles.

\subsection{Experimental Setup and Filtration Experiments}

\subsubsection{Filtration Setup}

Filtration experiments were carried out using a commercially available acrylic flat-sheet cross-flow cell (CF042 Sterlitech, Kent, WA, USA) with an active membrane surface area of $42 \mathrm{~cm}^{2}$ (Figure 1). For contacting the electrodes, titanium foils are introduced into the cell and are connected to the potentiostat (PGU, IPS Elektroniklabor GmbH, Münster, Germany).

(a)

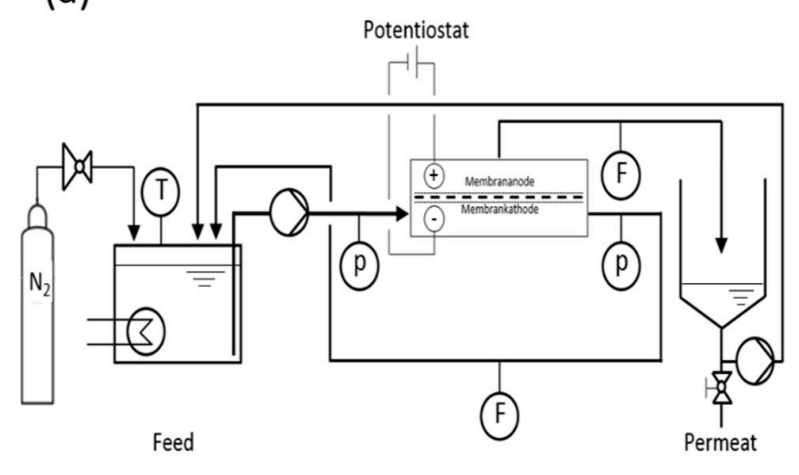

(b)

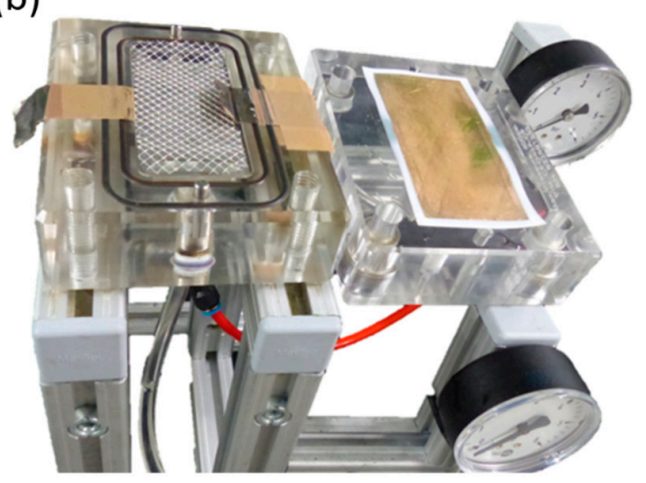

Figure 1. (a) Filtration setup; (b) Opened cross-flow cell (modified CF042) with titanium contacts, counter electrode, spacer and gold coated ultrafiltration (UF) membrane.

For dead-end mode, the cross-flow pump (MCP-Z Ismatech, Wertheim, Germany) is not operated and the pressure is applied through nitrogen gas and a pressure control valve (Swagelok, OH, USA). For cross-flow experiments, the cross-flow pump operates at a volume flow of $400 \mathrm{~mL} \mathrm{~min}{ }^{-1}$, which leads to a cross-flow velocity of approximately $0.16 \mathrm{~m} \mathrm{~s}^{-1}$. The permeate is pumped back to the feed and pressure tank of 20 L volume (Millipore Corp., Billerica, MA, USA). In all experiments, a constant transmembrane pressure (TMP) of 1 bar was applied and permeate flow was controlled by a variable area flowmeter (Kobold Messring $\mathrm{GmbH}$, Hofheim, Germany). The temperature of the feed solution was maintained under constant ambient conditions $\left(20-22^{\circ} \mathrm{C}\right)$. As counter electrode, a stainless steel sheet of $0.5 \mathrm{~mm}$ thickness is used. To avoid shortcuts between membrane-electrode and counter electrode, a plastic mesh spacer with a thickness of $1 \mathrm{~mm}$ is placed between both electrodes. The distance between the electrodes is $2 \mathrm{~mm}$. 


\subsubsection{Feed Solution}

SRNOM Standards (2R101N) was obtained from the International Humic Substances Society (IHSS, Denver, CO, USA). The SRNOM is a well-described NOM standard with a known size distribution from $0.3-500 \mathrm{~g} \mathrm{~mol}^{-1}$ including low molecular fulvic acids and high molecular humic acids $[18,19]$. Because of the wide molecular weight distribution, SRNOM is suitable to characterize the rejection performance of a UF membrane with UV-VIS method [18]. The stock solution was prepared at $100 \mathrm{mg} \mathrm{L}^{-1}$ in pure water and dissolved overnight at room temperature with stirring at $300 \mathrm{rpm}$ and then filtered by syringe through a $0.20 \mu \mathrm{m}$ membrane (DuraPES200, Membrana GmbH, Wuppertal, Germany). Feed solution was prepared by diluting the stock solution to a concentration of $6 \mathrm{mg}$ $\mathrm{L}^{-1}$. The $\mathrm{pH}$ was adjusted with sodium hydroxide or hydrochloric acid (Carl Roth GmbH + Co KG, Karlsruhe, Germany) and ionic strength of the solution was elevated by adding sodium chloride (Carl Roth $\mathrm{GmbH}+\mathrm{Co}$ KG, Germany). Electric conductivity and $\mathrm{pH}$ were determined with LF 315 and pH 340i (WTW Xylem GmbH, Weilheim, Germany), respectively.

\subsubsection{Filtration Experiments}

The impact of $\mathrm{pH}$, the ionic strength of feed solution as well as the applied membrane surface potential on filtration performance was investigated. All experiments are conducted as triplicates (or more). Surface potential of the electrode was measured by an additional experiment with $\mathrm{Ag} / \mathrm{AgCl}$ reference electrode (Xylem Analytics GmbH, Meinsberg, Germany) in a beaker, as the electrode could not be directly placed into the filtration cell (see Section 2.2.6). It was tested neutral, negative and positive surface potentials for filtration experiments (Table 1). For this, the membrane was used as a flow-through electrode (either cathode or anode). The samples from cross-flow filtration experiments were taken after $250 \mathrm{~mL}$ of permeate volume. Rejection of NOM was measured through TOC (Shimadzu, TOC-L CPH) and spectral absorption coefficient at a wavelength of $254 \mathrm{~nm}\left(\mathrm{UV}_{254}\right.$ or $\mathrm{SAC}_{254}$ ) with a $50 \mathrm{~mm}$ cuvette (DR500, Hach Lange, Düsseldorf, Germany). $\mathrm{UV}_{254}$ is proved to have good linear correlation with TOC of SRNOM $[3,7,20]$ and was primarily used for rejection calculation. Filtration volume is chosen small to avoid the influence of NOM fouling on membrane rejection by adsorption onto the membrane surface and into the pores [5,21]. In other experiments, the membrane was first charged negatively and after $250 \mathrm{~mL}$ of filtration, charge was switched positively (e.g., from -1 to $+1 \mathrm{~V}$ vs. $\mathrm{Ag} / \mathrm{AgCl}$ ). Immediately after the change of electrical polarity, samples were taken.

Prior to experiments, the membranes were rinsed in pure water (Milli-Q) for at least $24 \mathrm{~h}$. Membranes that were used in a previous experiment were cleaned in sodium hydroxide ( $\mathrm{pH}$ 11.5) solution for $24 \mathrm{~h}$ and used again if the initial pure water permeability was reached. Investigated parameters of filtration experiments are shown in Table 1. All experiments were conducted at TMP of 1 bar and a cross-flow of $400 \mathrm{~mL} \mathrm{~min}^{-1}$, equivalent to a cross-flow velocity of $0.16 \mathrm{~m} \mathrm{~s}^{-1}$.

Table 1. Parameters of filtration experiments.

\begin{tabular}{|c|c|c|c|}
\hline Tested Parameter & Membrane Surface Potential & pH of Feed & Ionic Strength Feed \\
\hline Membrane Surface Potential & $\begin{array}{c}-500,-1000,-1500,+500,+1000,+1500, \\
0 \mathrm{mV} \text { vs. } \mathrm{Ag} / \mathrm{AgCl}\end{array}$ & 7 & $1 \mathrm{mmol} \mathrm{L}^{-1}$ \\
\hline $\mathrm{pH}$ of Feed & $0,-1000 \mathrm{mV}$ & $4,7,10$ & $1 \mathrm{mmol} \mathrm{L}^{-1}$ \\
\hline Ionic Strength Feed & $0,-1000 \mathrm{mV}$ & 7 & $0,1,10 \mathrm{mmol} \mathrm{L}^{-1}$ \\
\hline
\end{tabular}

In order to evaluate the SRNOM rejection of the externally charged gold-UP150, additional cross-flow filtration experiments-with the same filtration parameters but with tighter UF membranes-were conducted (PES-UP020, MWCO $20 \mathrm{kDa}$, pore size $11 \mathrm{~nm}$ and PES-UP005, MWCO $5 \mathrm{kDa}$, pore size $6 \mathrm{~nm}$, both Microdyn-Nadir, Wiesbaden, Germany). 


\section{Results}

\subsection{Membrane Characterization}

Due to the sputter coating of the membrane, pure water permeability decreases by $40 \%$ compared to the virgin membrane (Figure 2a). Similar results were obtained by Gaedt et al. [12] after membrane coating. However, the thickness of the gold layer $(5,10$ or $15 \mathrm{~nm}$ ) obviously did not affect the resulting permeability considerably. The coating of the membrane (Figure $2 b$ ) does not visibly change the contact angle. As expected, the virgin PES membrane showed a negative surface charge. By coating with gold, the zeta potential increased (less negative) compared to the virgin membrane (Figure 2c). From the error bars, it can be seen that Au-surface coating led to considerably higher measuring inaccuracy of zeta potential. Likely, the decreased roughness of the membrane surface is a reason for this [16]. Literature data of the zeta potential of gold surfaces [22] shows similar zeta potential properties as the sputtered membrane. Differences in MWCO of the coated membrane and virgin membrane are rather small or not existing, following the definition, that $90 \%$ rejection marks the nominal MWCO (Figure 2d).

(a)

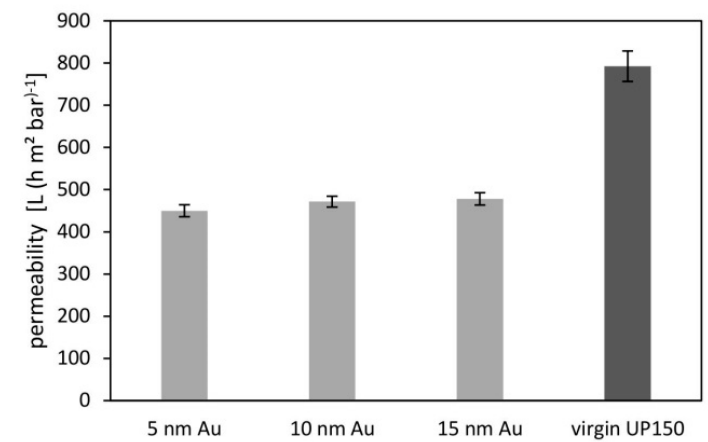

(c)

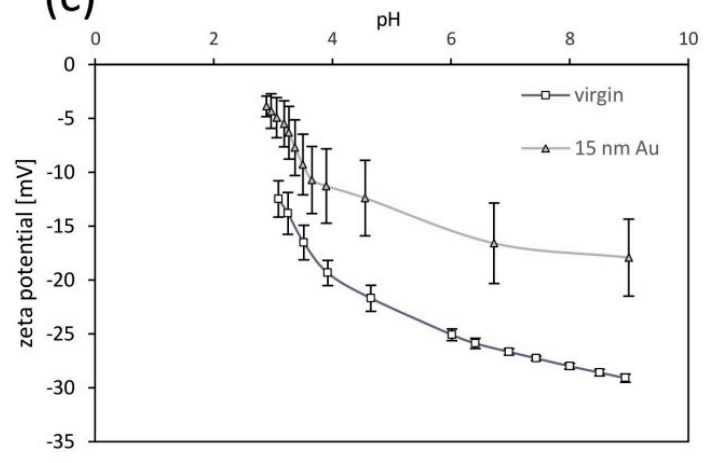

(b)

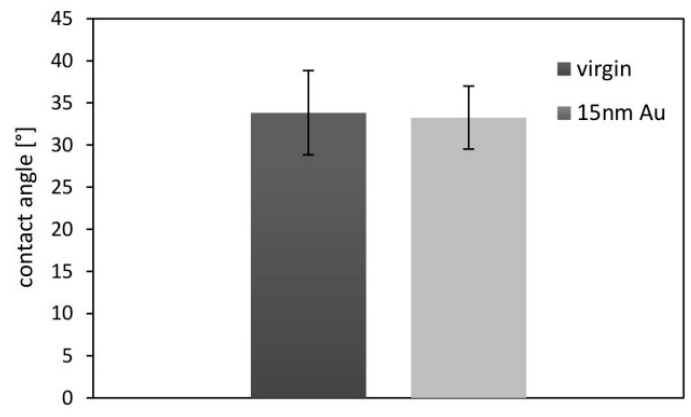

(d)

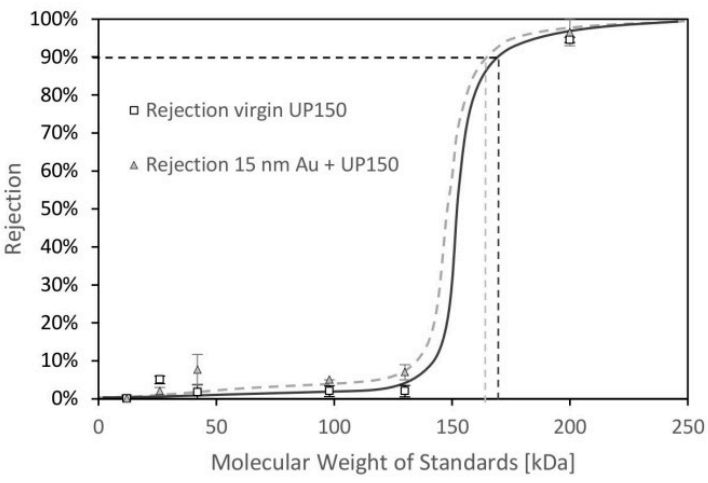

Figure 2. Membrane characterization virgin vs. gold coated UP150: (a) pure water permeability; (b) contact angle; (c) Zeta potential at $1 \mathrm{~mol} \mathrm{~L}^{-1} \mathrm{KCl}$; (d) molecular weight cut-off with estimated separation curves, error bars present standard deviations.

SEM imaging gives an impression of the pore size and the pore size distribution of the virgin membrane (Figure 3a) and the coated membrane (Figure 3b). No annular pores can be identified after the surface modification by a $15 \mathrm{~nm}$ gold layer. The Au-surface seems to be generally porous and cracked. Size of pores of the virgin UP150 is given by the manufacturer at $26 \mathrm{~nm}$. This was confirmed by the SEM imaging. The lengths of cracks in the gold layer are about 1-2 $\mu \mathrm{m}$ and width is approximately $0.05 \mu \mathrm{m}$. However, for the SEM imaging, the membrane had to be dried first which could have led to an enlargement of the cracks due to the shrinking of the membrane. 

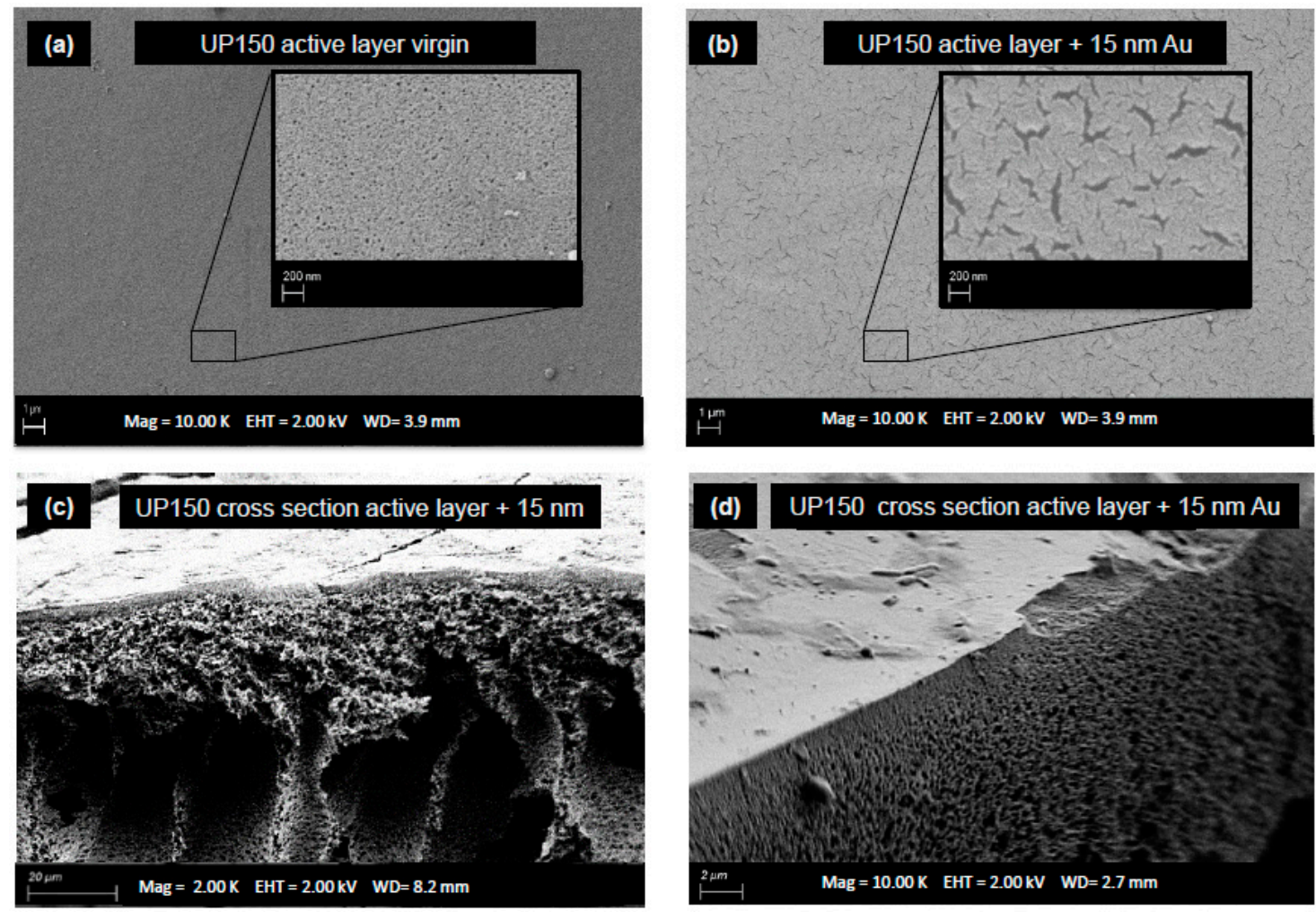

Figure 3. Scanning electron microscopy (SEM) imaging: (a) virgin UP150 with $3.6 \mathrm{~nm}$ Au coating for SEM contrast, $10 \mathrm{k} \times$ and $100 \mathrm{k} \times$; (b) UP150 + $15 \mathrm{~nm} \mathrm{Au,} 10 \mathrm{k} \times$ and $100 \mathrm{k} \times$; (c) cross section of coated membrane, $2 \mathrm{k} \times$; (d) cross section of active layer $+15 \mathrm{~nm} \mathrm{Au}, 10 \mathrm{k} \times$.

Cyclic voltammetry experiments (Figure 4a) show that with increasing ionic strengths and electric conductivity of the feed solution, the current increased as well. However, no specific peaks can be observed, which leads to the conclusion that electrochemical reactions are negligible during the filtration experiment [23]. Furthermore, experiments showed that the distribution of the applied potential to cathode and anode was almost equally distributed. When applying $2 \mathrm{~V}$ of cell voltage with the potentiostat, anode surface potential was measured at $+1 \mathrm{~V}$ vs. $\mathrm{Ag} / \mathrm{AgCl}$ and cathode surface potential was $-1 \mathrm{~V}$ vs. $\mathrm{Ag} / \mathrm{AgCl}$. For a membrane surface potential of $\pm 1 \mathrm{~V}$ vs. $\mathrm{Ag} / \mathrm{AgCl}$, a current of around $\pm 1 \mathrm{~mA}$ is measured for a surface area of $42 \mathrm{~cm}^{2}$, leading to a current density of $0.024 \mathrm{~mA}$ $\mathrm{cm}^{-2}$, which can be considered as too low for significant electrochemical activity [7]. The experiments also showed that the membrane coating remains stable up to relatively high [23] catholic and anodic potentials up to $\pm 4 \mathrm{~V}$ vs. $\mathrm{Ag} / \mathrm{AgCl}$.

Investigation of surface conductivity after sputter coating of the membrane shows that the layer thickness $(5,10$ and $15 \mathrm{~nm} \mathrm{Au}$ ) has a major impact on the resulting conductivities (Figure $4 \mathrm{~b}$ ). This can be explained by the proceeding coverage of the virgin surface with gold. Other studies claim that, depending on the surface roughness and morphology, at least $10 \mathrm{~nm}$ of gold is needed to generate a homogeneous and completed gold surface overcoming occurring isolated Au-clusters [12,24]. 
(a)

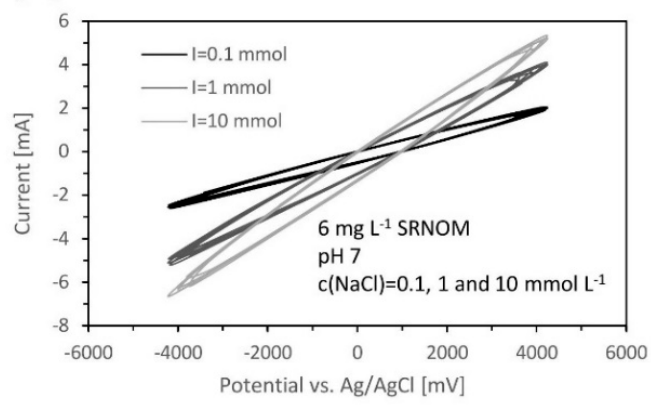

(c)

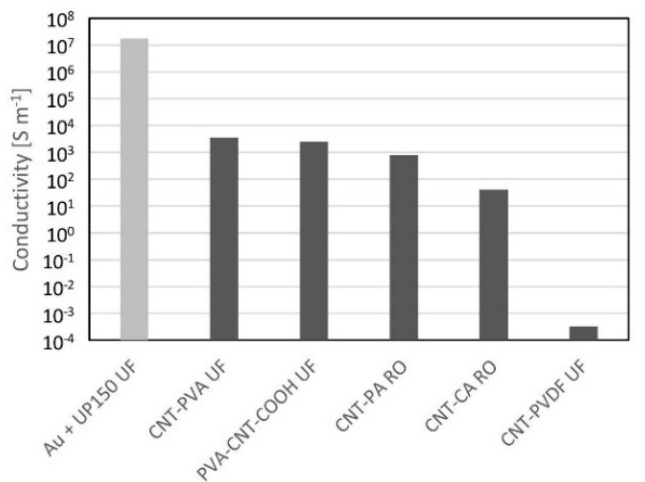

(b)

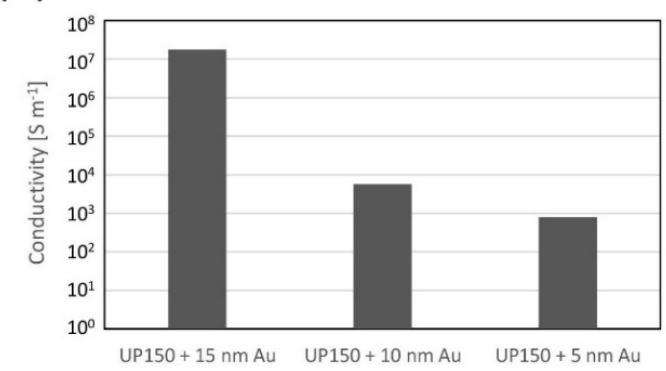

(d)

\begin{tabular}{lr}
\multicolumn{2}{c}{ Literature data of conductive membranes } \\
Membrane & Conductivity [S/m] \\
15 nm Au coated UP150 & $1.77 \times 10^{7}$ \\
CNT-PVA UF (Lannoy et al. 2012) & $3.60 \times 10^{3}$ \\
PVA-CNT-COOH UF (Dudchenko et al. 2014) & $2.50 \times 10^{3}$ \\
CNT-PA RO (Nolte 2009) & $7.86 \times 10^{2}$ \\
CNT-CA RO (Nolte 2009) & $4.04 \times 10^{1}$ \\
CNT-PVDF UF (Zhang und Vecitis 2014) & $3.20 \times 10^{-4}$
\end{tabular}

Figure 4. Electrochemical characterization of membrane: (a) cyclic voltammetry of Au coated UP150 in Suwannee River Natural Organic Matter (SRNOM) solution of $6 \mathrm{mg} \mathrm{L}^{-1}$ at $0.1,1$ and $10 \mathrm{mmol} \mathrm{L}^{-1} \mathrm{NaCl}$ (scan rate $100 \mathrm{mV} \mathrm{s}^{-1}$ ); (b) surface conductivity vs. thickness of gold layer; (c) surface conductivity vs. literature values of CNT membranes; (d) literature data of conductive membranes.

Through utilization of a sputtered gold layer of $15 \mathrm{~nm}$, a relatively high surface conductivity is generated. Compared to the recently developed carbon nanotube (CNT) membranes [7,23,25,26], the conductivity is at least three orders of magnitudes higher (Figure $4 c, d$ ).

Taking into account the small currents flowing during electro-repulsive membrane filtration experiments [27], and considering Ohm's law, it is probably not necessary to have moderately high surface conductivities to see an effect on fouling and rejection behavior. This is also proved by the results of several mentioned publications, which focus on fouling mitigation. Though, by using the membrane for electro-oxidation [28-30] or electro-reduction [31] reactions, the conductivity does have a major influence on the filtration performance [9].

\subsection{Filtration Experiments}

\subsubsection{Effects of Cathodic and Anodic Potentials}

Dead-end filtration of the SRNOM feed solution without applied potential confirm that there is only $6 \% \mathrm{UV}_{254}$ rejection (Figure $5 \mathrm{a}$ ), which is based on steric exclusion effects [3,32]. Rejection of $28 \%$ can be measured during cross-flow filtration without applied potential. This leads to the conclusion that the increased rejection is mostly based on electrostatic repulsion, which is the rejection mechanism that is mainly affected by concentration polarization $[3,5]$.

No significant change in rejection was observed by applying $-0.5 \mathrm{~V}$ vs. $\mathrm{Ag} / \mathrm{AgCl}$. However, when raising surface potential to $-1 \mathrm{~V}$ vs. $\mathrm{Ag} / \mathrm{AgCl}$ the $\mathrm{UV}_{254}$ rejection abruptly increases from $28 \%$ to $60 \%$. Obviously, the application of negative potential to membrane surface leads to the enhancement of rejection with increasing potential, though the rejection enhancement is not proportional to the applied potential. A similar behavior was also observed by other authors $[7,23,33]$ and might be 
explained by the concept of counteracting drag force and electrostatic repulsion force which results in a critical electric field or respective applied surface potential $[23,33]$. Through further increase of voltage to $-1.5 \mathrm{~V}$ vs. $\mathrm{Ag} / \mathrm{AgCl}, \mathrm{UV}_{254}$ rejection reached up to $64 \%$. Corresponding permeability of the negatively charged membranes shows that with increasing negative potential and respective increasing rejection, permeability decreases (Figure $5 b$ ). This is probably connected with a growing influence of concentration polarization [34]. This assumption is supported by the observation of a sudden increase of flux and decrease of rejection after changing surface potential from $-1 \mathrm{~V}$ to $+1 \mathrm{~V}$ vs. $\mathrm{Ag} / \mathrm{AgCl}$ during the experiment (see Section 3.2.3).

Comparing the $\mathrm{UV}_{254}$ rejection rate of commercial 20 and $5 \mathrm{kDa}$ membranes to the externally charged $150 \mathrm{kDa}$ membrane, it can be stated that due to the applied potential of $-1.5 \mathrm{~V} \mathrm{vs}$. $\mathrm{Ag} / \mathrm{AgCl}$ the $150 \mathrm{kDa}$ membrane enhances rejection ability into the range of a $5 \mathrm{kDa}$ membrane. Throughout, the permeability of the externally charged UP150 is still more than three times higher than that of the $5 \mathrm{kDa}$ membrane.

When applying +0.5 and $+1 \mathrm{~V}$ vs. $\mathrm{Ag} / \mathrm{AgCl}$, no observable effects on $\mathrm{UV}$ rejection rate can be observed; permeability is also unchanged in relation to the uncharged membrane. With application of $+1.5 \mathrm{~V}$ vs. $\mathrm{Ag} / \mathrm{AgCl}, \mathrm{UV}_{245}$ rejection increases to $45 \%$ while corresponding permeability does not decrease (Figure $5 b$ ). Rejection enhancement at $+1.5 \mathrm{~V}$ vs. $\mathrm{Ag} / \mathrm{AgCl}$ might be explained by electro-sorption of negatively charged NOMs onto the positive membrane surface.

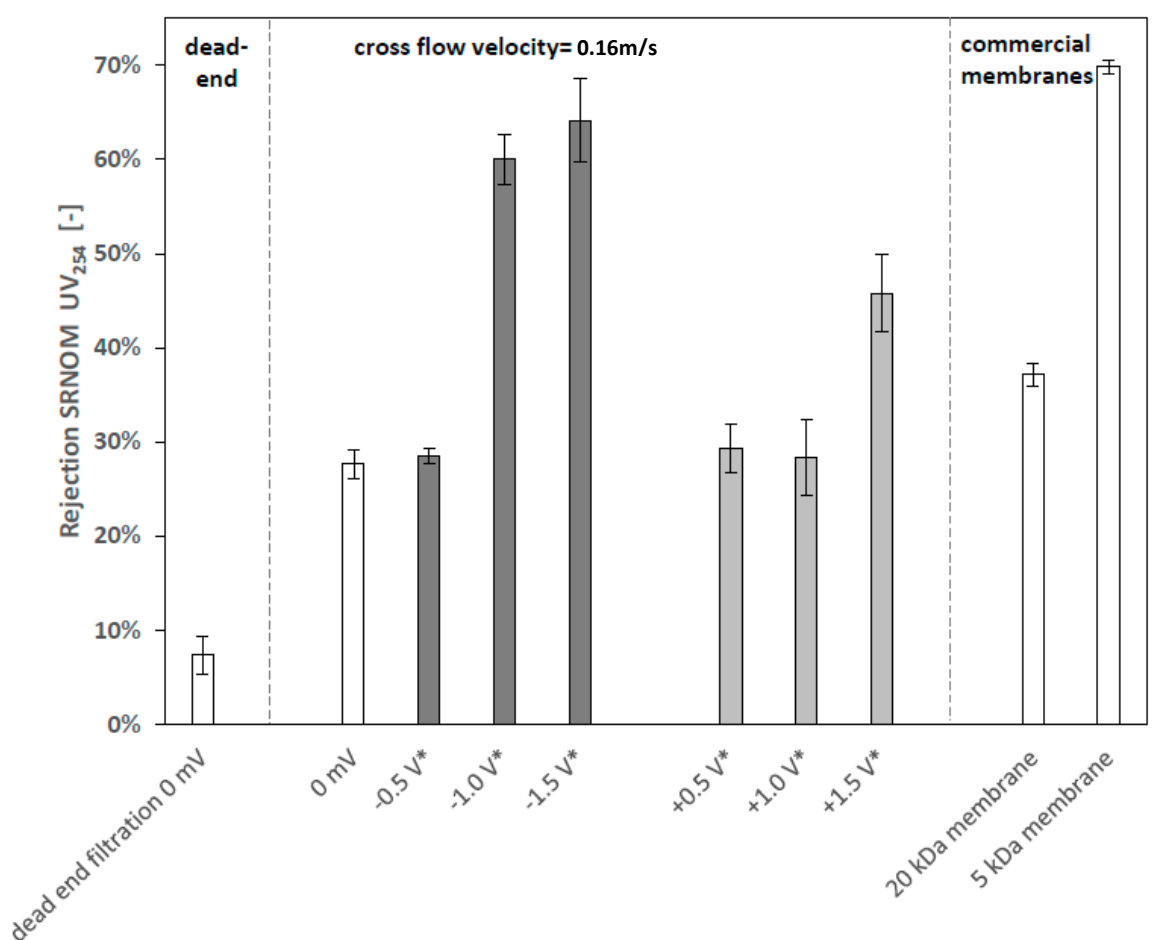

(a)

Figure 5. Cont. 


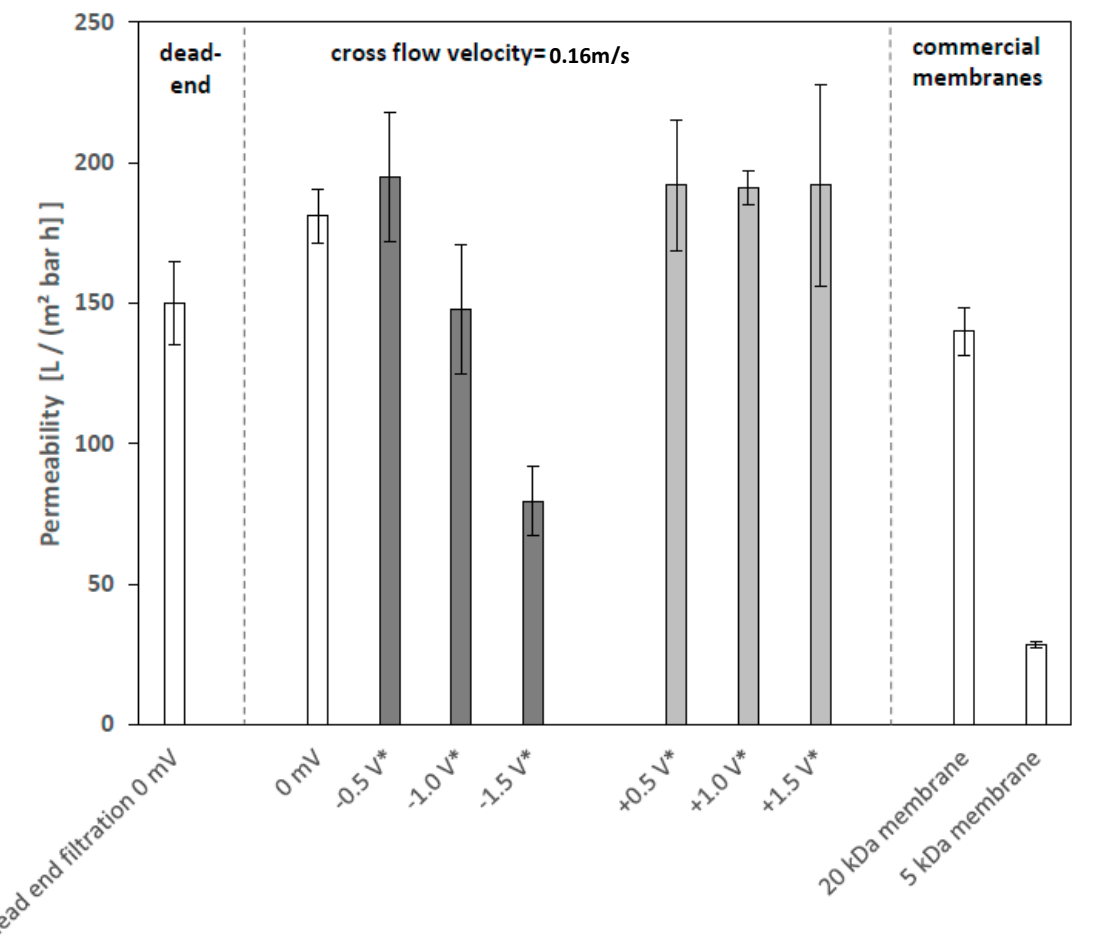

(b)

Figure 5. $\mathrm{UV}_{254}$ rejection rates and permeability data; all experiments are conducted at least in triplicates with membrane surface of $42 \mathrm{~cm}^{2}$, transmembrane pressure (TMP) of 1 bar, cross-flow velocity of $0.16 \mathrm{~m} \mathrm{~s}^{-1}$ (except of dead-end experiment), sample for rejection calculation is taken after filtration of $250 \mathrm{~mL}$, feed: $6 \mathrm{mg} \mathrm{L}^{-1}$ of SRNOM, $1 \mathrm{mmol} \mathrm{L}^{-1} \mathrm{NaCl}$, pH 7; (a) rejection data after $250 \mathrm{~mL}$ of filtration; (b) permeability data after $250 \mathrm{~mL}$ of filtration, * all potentials are measured vs. $\mathrm{Ag} / \mathrm{AgCl}$ reference electrode, error bars present standard deviations.

Dudchenko et al. [23] also observed strong fouling enhancement of an electro-conductive UF membrane through filtration of sodium alginate solution when positive potentials were applied. This can be interpreted as an electro-sorption onto the membrane surface as well, with the difference that relatively large alginate molecules were not able to pass membrane pores as NOM molecules can do.

\subsubsection{Influence of Ionic Strengths and $\mathrm{pH}$}

As expected, the ionic electrolyte background shows to have a major influence on rejection behavior (Figure 6a). Other authors revealed that ultrafiltration membranes show less rejection of NOMs with increasing ionic strengths $[1,35]$. It is considered that with raising ionic strengths the shielding of the organic molecules is also increasing, which leads to a lesser effective surface charge. The same applies to the membranes surface itself [1]. At high charge and low ionic strengths, the NOM molecules are more linear stretched because of repulsive functional groups (carboxylic groups), and at low charge and higher $\mathrm{pH}$ the NOM molecules curl up and have a more compact structure [36].

However, experiments indicate that the concentration of $1 \mathrm{mmol} \mathrm{L}^{-1} \mathrm{NaCl}$, compared to no ionic background, led to an increase of rejection of the externally charged and uncharged membrane. This might be explained by the higher electrical double-layer capacitance induced by the rise of the ionic strengths [7]. With almost no ions in the feed solution, no double layer can be formed. This can also be seen by the results of cyclic voltammetry. At low ionic concentrations, flowing current is much lesser. Shao et al. [5] observed the same results by filtration of humic acids (at ionic strengths of 0 and $3 \mathrm{mmol} \mathrm{L}-1$ ) with neutral and negatively charged UF membranes. Specific adsorption of ions might be a reason for increased rejection also [37]. 
At ionic strengths of $10 \mathrm{mmol} \mathrm{L}^{-1}, \mathrm{UV}_{254}$ rejection rate decreases to $10 \%$. At this ion concentration, the repulsion of electrostatic field might collapse and the remaining rejection bases mainly on steric exclusion. At this ionic strength, external charging of the membrane cannot enhance the rejection rate any further.

At $\mathrm{pH} 4$, rejection is only about $10 \%$, which can be considered the fraction, which is rejected by steric exclusion (Figure 6b). Below pH 4.7, SRNOM is neutrally charged [38], therefore no electrostatic repulsion is present. Furthermore, the $\mathrm{pH}$ at point of zero charge $\left(\mathrm{pH}_{\mathrm{pzc}}\right)$ of gold is 4.9 [39]. In this regard, it is plausible that the application of negative potential of $-1 \mathrm{~V}$ vs. $\mathrm{Ag} / \mathrm{AgCl}$ does not result in further impact on rejection. At pH 7, rejection increases to $29 \%$ for the not externally charged membrane. This might be explained by the negative zeta potential that naturally develops at the membrane's gold surface even without connected potentiostat [22]. At pH 7, deprotonation of carboxylic groups of the NOMs are almost completed. However, negative charge density of NOMs is still increasing by raising the $\mathrm{pH}$ to 10 [40]. Nevertheless, no additional rejection can be observed at $\mathrm{pH} 10$ compared to $\mathrm{pH} 7$.

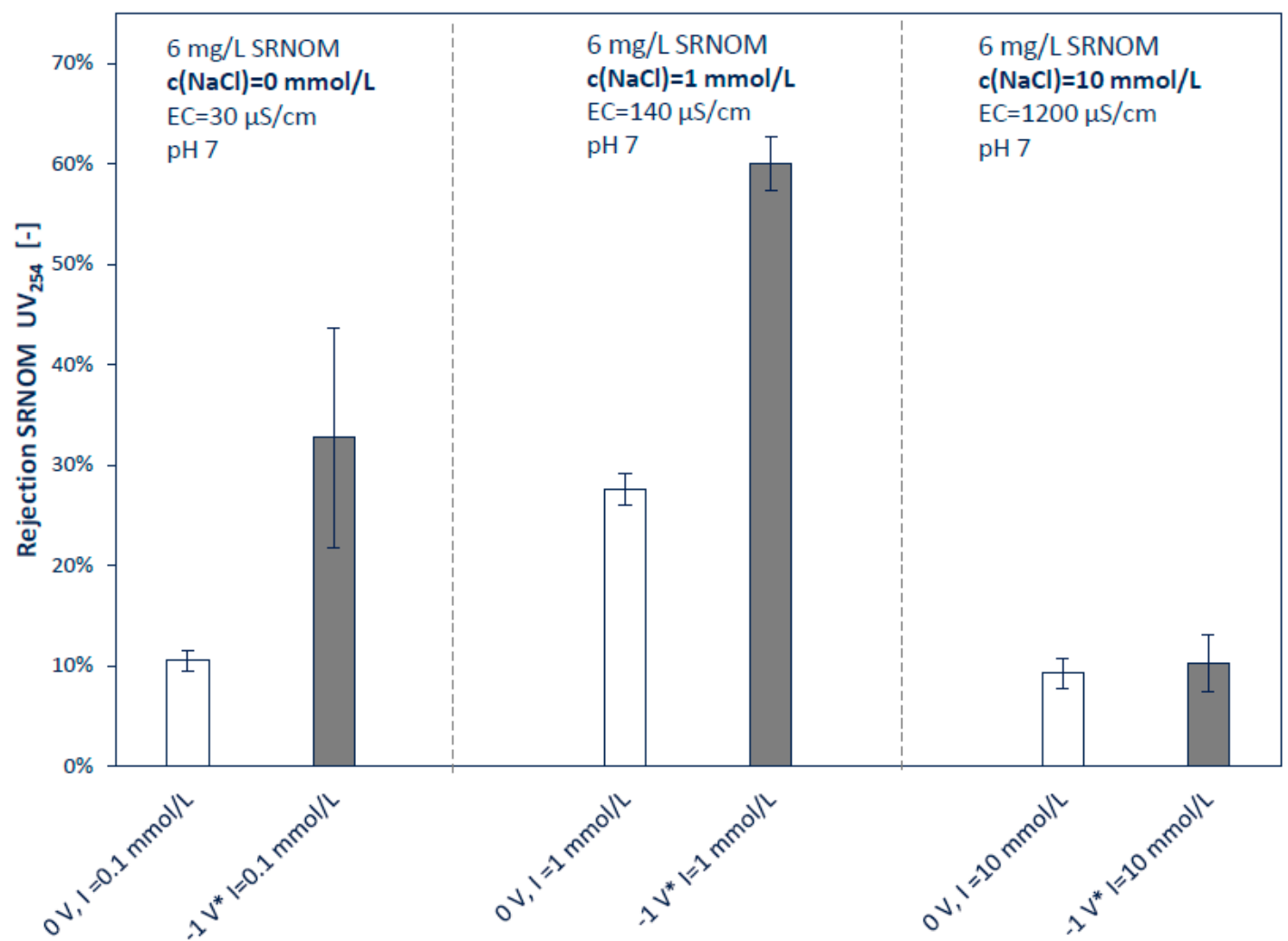

(a)

Figure 6. Cont. 


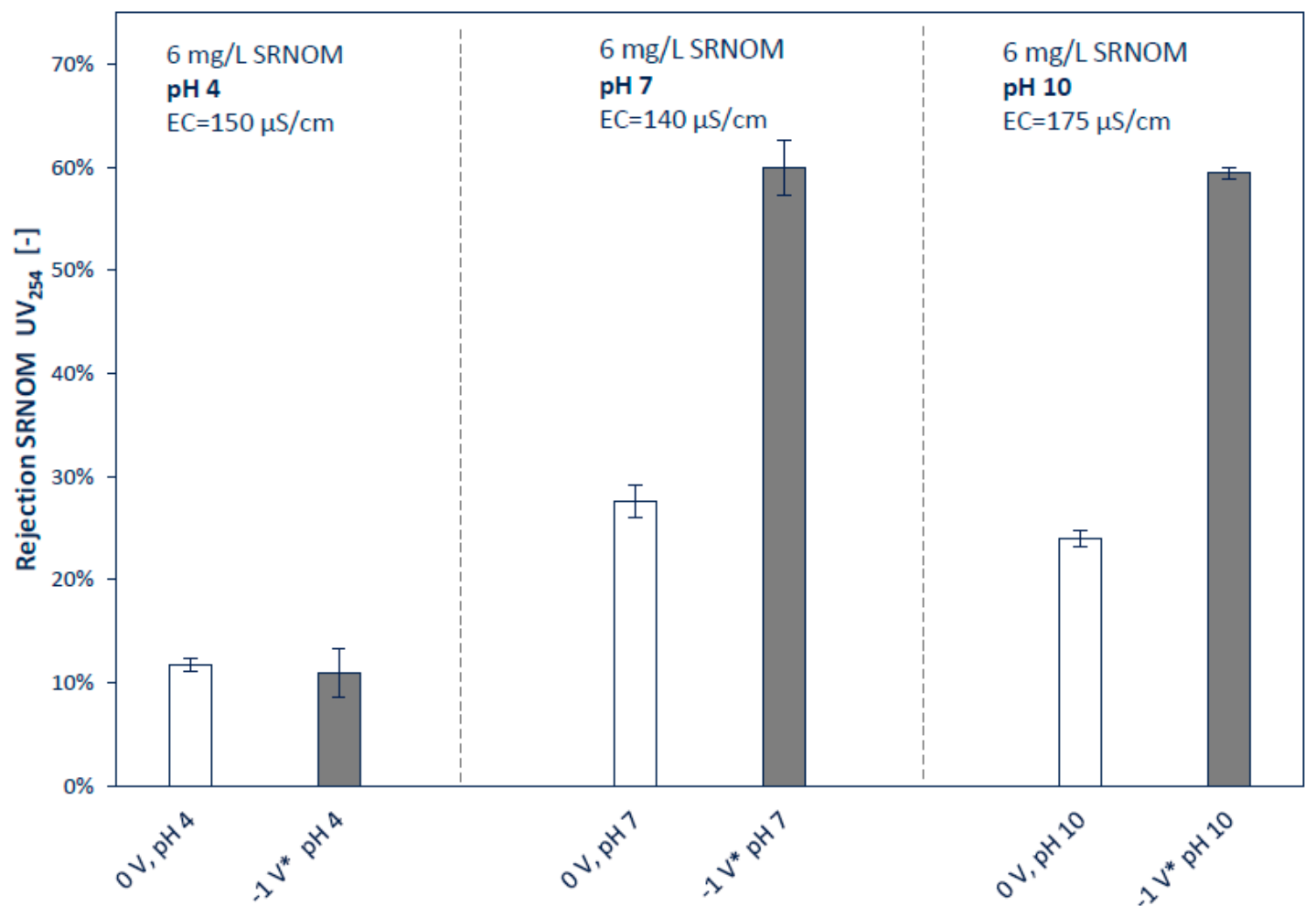

(b)

Figure 6. Influence of ionic strengths (a) and $\mathrm{pH}(\mathbf{b})$ on rejection; all experiments are conducted at least as triplicate with a membrane surface of $42 \mathrm{~cm}^{2}$, TMP of $0.1 \mathrm{MPa}$, cross-flow velocity of $0.16 \mathrm{~m}$ $\mathrm{s}^{-1}$, sample for rejection calculation is taken after filtration of $250 \mathrm{~mL}$; feed: $6 \mathrm{mg} \mathrm{L}^{-1}$ of SRNOM, $\mathrm{pH} 7, \mathrm{NaCl}$ concentration of (a) 0,1,10 $\mathrm{mmol} \mathrm{L}^{-1}$, (b) $\mathrm{pH} \mathrm{4,7}$ and 10; * all potentials are measured vs. $\mathrm{Ag} / \mathrm{AgCl}$ reference electrode, error bars present standard deviations.

\subsubsection{Changing Sign of Surface Potential during Filtration}

For further investigation on the impact of surface charge, the potential was changed during running filtration experiments. Immediately after the change of signs from negative to positive surface charge, the rejection decreases and the flux increases (Figure 7a). The increase of flux might be explained by the decay of previously developed concentration polarization [34]. The effect of increasing flux is even more pronounced when the applied potential was more elevated $( \pm 1.5$ instead of $\pm 1 \mathrm{~V}$ ) (Figure $7 \mathrm{~b}$ ). After changing potential from -1.5 to $+1.5 \mathrm{~V} \mathrm{vs.} \mathrm{Ag} / \mathrm{AgCl}$, a negative rejection of $-5 \%$ was measurable for a short time, which supports the hypothesis of an electrostatically induced concentration polarization, which decays away by the change of signs. Another explanation for negative $\mathrm{UV}_{254}$ rejection rates might be the sudden desorption of NOMs from the membrane's surface. However, this explanation seems unlikely as the surface was negatively charged like the NOMs, which does not facilitate adsorption. 


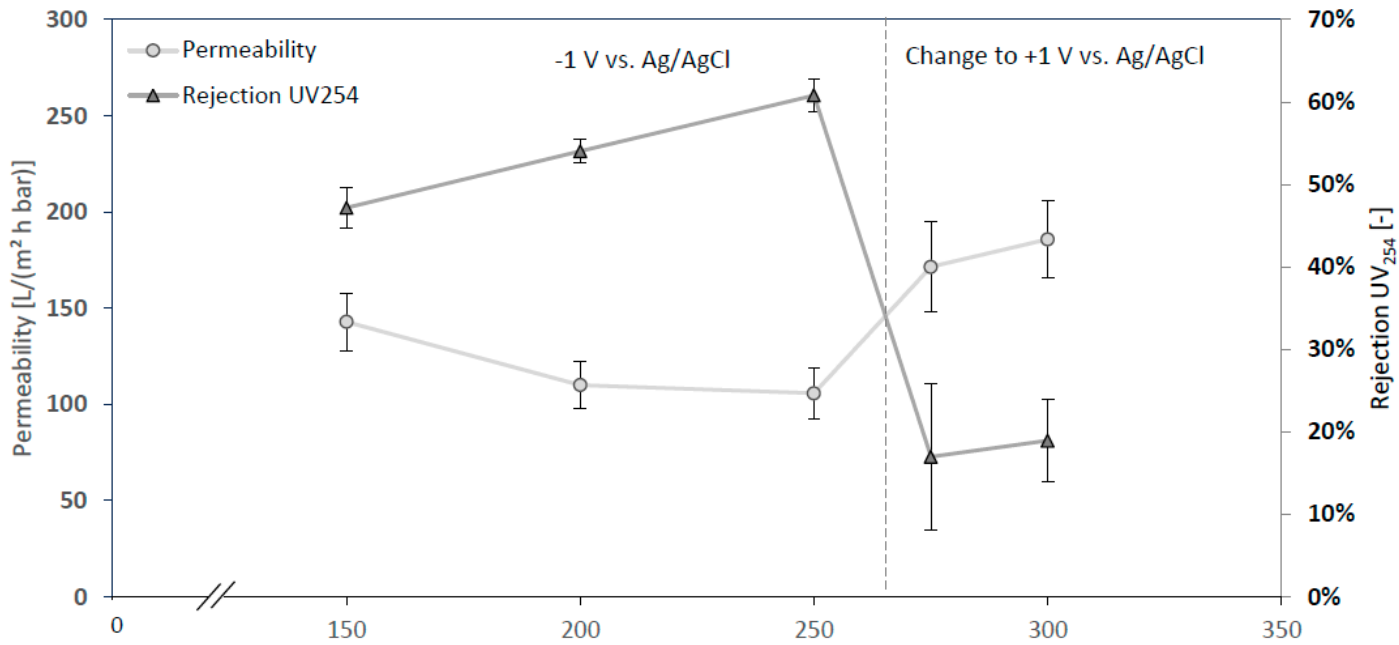

(a)

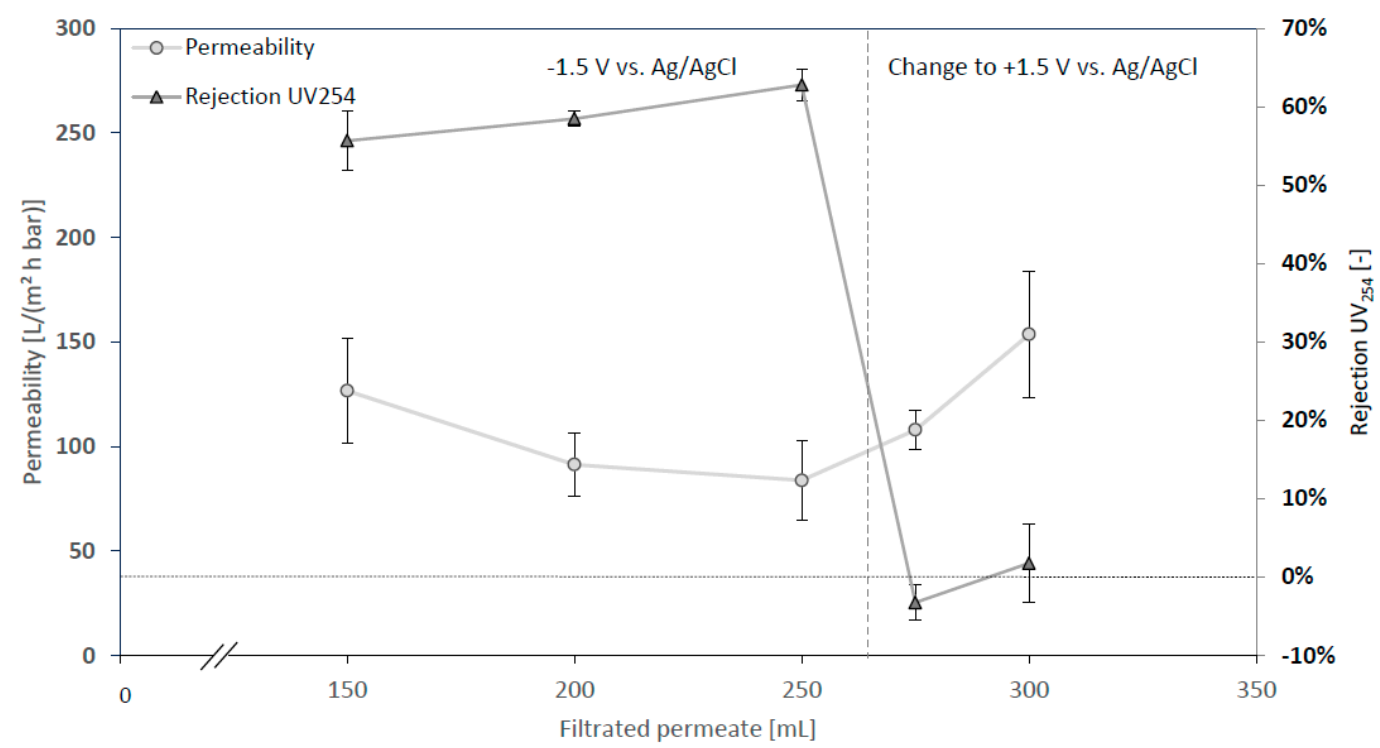

(b)

Figure 7. Filtration experiment with changing surface potentials; feed: $6 \mathrm{mg} \mathrm{L}^{-1}$ of SRNOM, $1 \mathrm{mmol}$ $\mathrm{L}^{-1} \mathrm{NaCl}, \mathrm{pH} 7$; (a) applied surface potential $-1 \mathrm{~V}$ changed to $+1 \mathrm{~V}$ vs. $\mathrm{Ag} / \mathrm{AgCl}$ after $250 \mathrm{~mL}$ filtration; (b) applied surface potential $-1.5 \mathrm{~V}$ changed to $+1.5 \mathrm{~V}$ vs. $\mathrm{Ag} / \mathrm{AgCl}$ after $250 \mathrm{~mL}$ filtration; error bars present standard deviations.

\section{Discussion and Conclusions}

\subsection{Membrane Modification with Gold Sputter Coating}

Sputter coating of UF membranes with ultrathin gold layers is a simple and suitable method to transform a commercial flat sheet membrane into an electro-conductive UF membrane. A 40\% decrease in permeability results under the present conditions; nevertheless, other parameters as MWCO or hydrophobicity remained unchanged (see Section 3.1). SEM imaging confirms the development of a secondary gold layer on the membrane surface when $15 \mathrm{~nm}$ of gold was sputtered. Accordingly, resulting permeability decrease is presumably caused by higher filtration resistance due to the additional passage of water through the secondary layer of gold and not because of the reduction of the nominal pore size of the membrane [12]. 
The resulting surface conductivity after $15 \mathrm{~nm}$ gold coating is relatively high; compared with CNT membranes, it is three orders of magnitudes higher (see Figure 4c). Accordingly, Au-coating of only $5 \mathrm{~nm}$ gold on the present PES-UF membrane is enough to obtain sufficient surface conductivities. Another advantage of Au-coating is its chemical stability. The membranes can be used as anode and cathode which is not possible with widely investigated CNT membranes $[25,26]$. These membranes are only stable to cell potential of $1.5 \mathrm{~V}$ when the CNT membrane is used as an anode [23]. No decrease of surface conductivity was evident after filtration experiments even if the membrane was used for many times in a row; furthermore, no gold particles or deposits could be found at any time in the feed tank. This leads to the assumption that the coated gold layer is also mechanically stable and not affected by the shear stress of the applied cross-flow.

It might be interesting to utilize the present effects even on a commercial basis. Au-coating of polymer microfiltration, UF, and even nanofiltration membranes seems feasible. The additional material cost for gold coating of flat sheet membranes for a $15 \mathrm{~nm}$ coating sums up to around $8 \mathrm{US} \$ / \mathrm{m}^{2}$. Conceivably, it is possible to use titanium or silver instead of gold for more economic fabrication. By sputtering the counter electrode on the support layer of the membrane and the working electrode on the active layer, one urgent drawback of the implementation of electrical conductive membranes in spiral wound modules could be overcome [27], because no additional counter electrode is necessary. However, further studies on material stability, overall fouling, rejection and real water matrix behavior are necessary.

\subsection{Filtration Experiments with Applied Surface Potential}

The zeta potential has become the most important measurable reference for evaluating the surface charge of membranes [16,41]. An externally induced zeta potential is difficult to measure and complex to model $[39,42,43]$. It is influenced by several parameters as applied potential to the electrode, $\mathrm{pH}$, ionic strength, electrode distance and electrode material [5,44]. Duval et al. [22] modeled the double layer potential of a gold electrode which can be assumed to be comparable to the zeta potential with respect to applied potential, $\mathrm{pH}$ and ionic strengths [45]. Barten et al. [39] confirmed the results of the model with an experimental approach. Both found a strong dependence of ionic strengths and $\mathrm{pH}$ on the induced zeta potential. At ionic strengths of approx. $1 \mathrm{mmol} \mathrm{L}^{-1}$ the induced zeta potential diminishes to $1 / 10$ of the applied electrode potential vs. $\mathrm{Ag} / \mathrm{AgCl}$. Accordingly, the application of $-1000 \mathrm{mV}$ vs. $\mathrm{Ag} / \mathrm{AgCl}$ resulted in a zeta potential of $-99 \mathrm{mV}$ for $\mathrm{I}=1 \mathrm{mmol} \mathrm{L}^{-1},-65 \mathrm{mV}$ for $\mathrm{I}=10 \mathrm{mmol} \mathrm{L}^{-1}$ and $-35 \mathrm{mV}$ for $\mathrm{I}=100 \mathrm{mmol} \mathrm{L}^{-1}$.

The present results of filtration experiments on charged membranes confirm the earlier proposed electrostatic rejection mechanism [3-5,37]. In interplay with pore size, external negative surface charge led to an increase of NOM rejection starting at the potential of $-1 \mathrm{~V}$ vs. $\mathrm{Ag} / \mathrm{AgCl}$ (see Section 3.2.1). After lowering the molecule charge of the applied NOMs by the decreasing of $\mathrm{pH}$ or increasing of ionic strengths, NOM rejection enhancement effects induced by the externally applied potential was not pronounced anymore (see Section 3.2.2). Considering these, arguments that measured rejection rates are caused by chemical oxidation/reduction or the building gas bubbles (e.g. oxygen or hydrogen) on membrane surface are less convincing. In this case, rejection enhancement shall also be visible when NOMs charge is diminished. The external charging of the membrane probably still has an effect on the resulting zeta potential of the membrane at different ionic strengths [39], but because the NOMs are less charged, no electrostatic repulsion is induced.

Due to external charging, filtration performance can be improved considerably. The application of $-1.5 \mathrm{~V}$ vs. $\mathrm{Ag} / \mathrm{AgCl}$ on the Au-coated UF membrane with $150 \mathrm{kDa}$ MWCO results in rejection performance close to a $5 \mathrm{kDa}$ membrane at much higher permeability. Throughout, additional energy consumption due to membrane charging is approx. $0.001-0.01 \mathrm{kWh}$ per cubic meter filtrated water, which is negligible compared to necessary energy for pumping.

The change of sign of applied potential during the filtration experiment reveals that NOM rejection rate drops to zero after reversing potentials. Simultaneously, the corresponding flux is increasing (see Section 3.2.3). This results support the assumption that NOM rejection was caused mainly by 
electrostatic mechanisms. In Figure 8, a graphical model of NOM rejection based on the described observations is presented.

(a)

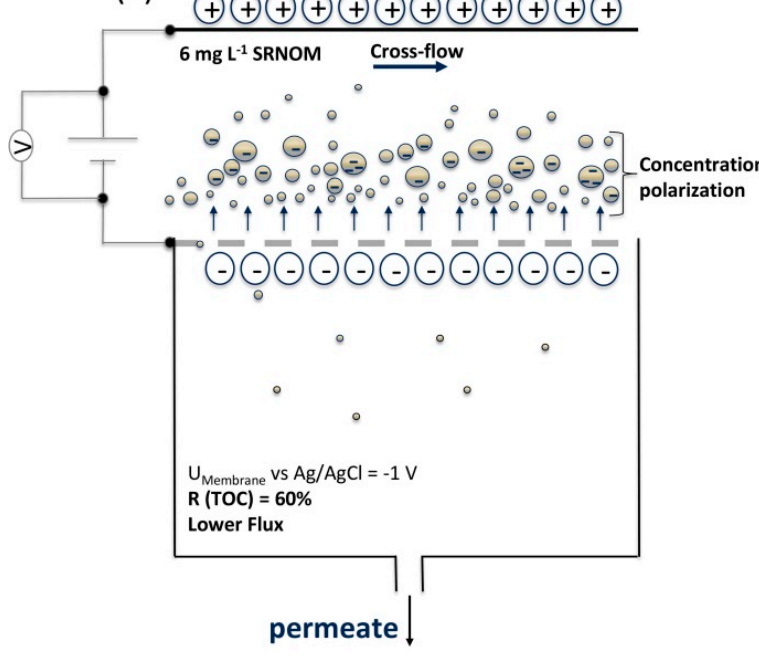

(b)

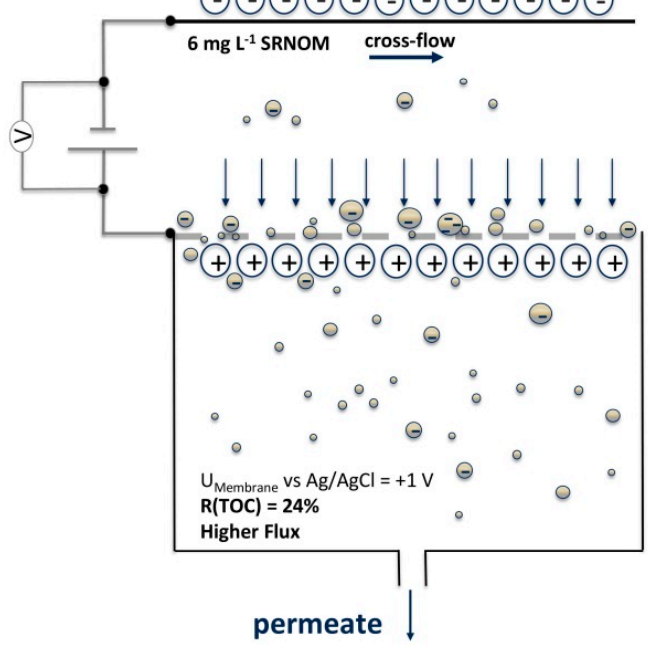

Figure 8. Model of NOM rejection on membrane surface with anodic and cathodic potential; (a) negatively charged membrane with high rejection due to electrostatic repulsion resulting in strong concentration polarization; (b) positively charged membrane with no electrostatic repulsion, higher flux and less rejection.

In conclusion, results show that in-situ charging of the investigated electro-conductive Au-membrane results in a possible functionalization of the material by tunable membrane charge. By this, a promising and in particular flexible tool is available to further evaluation of the impact of surface charge in UF membrane filtration with respect to the manifold separation tasks. This is part of ongoing research.

Supplementary Materials: The following are available online at http:/ / www.mdpi.com/2077-0375/8/3/64/s1. Figure S1: Contact Angle Measurement: (a) experimental set-up: A) camera B) Stand C) Box D, E, F) Sample holder G) lamps; (b) software aided analyses of contact angle (Foto: L. Gormsen), Figure S2: Electrical surface conductivity: Van-der-Pauw-Method (Nolte 2009) (a) scheme for contacting membrane (b) nomogram for determining correction factor (Van der Pauw 1958), Figure S3: Influence of ionic strengths and $\mathrm{pH}$ on rejection and corresponding permeability: all experiments are conducted at least as triplicate with membrane surface of $42 \mathrm{~cm}^{2}, \mathrm{TMP}$ of $0.1 \mathrm{MPa}$, cross-flow velocity of $0.16 \mathrm{~m} \mathrm{~s}^{-1}$, sample for rejection calculation is taken after filtration of $250 \mathrm{~mL}$; feed: $\mathrm{c}(\mathrm{SRNOM})=6 \mathrm{mg} \mathrm{L}^{-1}, \mathrm{pH} 7, \mathrm{c}(\mathrm{NaCl})=0,1,10 \mathrm{mmol} \mathrm{L}^{-1}$ (b) $\mathrm{pH} \mathrm{4,} 7$ and 10; *all potentials are measured vs. $\mathrm{Ag} / \mathrm{AgCl}$ reference electrode, error bars present standard deviations.

Author Contributions: T.M. and M.E. designed and conceived the experiments. P.B. and T.M. conducted the experiments and analyzed the data of membrane characterization with input of M.E., S.P. and T.M. conducted and evaluated the filtration experiments with input of M.E., whereas T.M. wrote the present manuscript.

Funding: This research was funded by the German Research Foundation (DFG) with Project No. 262559207.

Acknowledgments: The authors wish to thank Maximillian Meyer and Hannes Bunn for technical support of this study. Furthermore, we thank microscopy unit (BEEM) of Hamburg University of Technology for the assistance with SEM Imaging and Pierre Pötschick from $\mathrm{i}^{3}$ membrane $\mathrm{GmbH}$ for inspiring discussion regarding sputter deposition processes. The funding of DFG is greatly acknowledged.

Conflicts of Interest: The authors declare no conflict of interest. The funders had no role in the design of the study; in the collection, analyses, or interpretation of data; in the writing of the manuscript, and in the decision to publish the results. 


\section{References}

1. Schäfer, A. Natural Organics Removal Using Membranes: Principles, Performance, and Cost, 1st ed.; CRC Press: Boca Raton, FL, USA, 2001.

2. Van der Bruggen, B.; Vandecasteele, C.; Van Gestel, T.; Doyen, W.; Leysen, R. A review of pressure-driven membrane processes in wastewater treatment and drinking water production. Environ. Prog. 2003, 22, 46-56. [CrossRef]

3. Cho, J.; Amy, G.; Pellegrino, J. Membrane filtration of natural organic matter: Factors and mechanisms affecting rejection and flux decline with charged ultrafiltration (UF) membrane. J. Membr. Sci. 2000, 164, 89-110. [CrossRef]

4. Kopeć, K.K.; Dutczak, S.M.; Wessling, M.; Stamatialis, D.F. Tailoring the surface charge of an ultrafiltration hollow fiber by addition of a polyanion to the coagulation bore liquid. J. Membr. Sci. 2011, 369, 59-67. [CrossRef]

5. Shao, J.; Hou, J.; Song, H. Comparison of humic acid rejection and flux decline during filtration with negatively charged and uncharged ultrafiltration membranes. Water Res. 2011, 45, 473-482. [CrossRef] [PubMed]

6. Mehta, A.; Zydney, A.L. Effect of Membrane Charge on Flow and Protein Transport during Ultrafiltration. Biotechnol. Prog. 2006, 22, 484-492. [CrossRef] [PubMed]

7. Zhang, Q.; Vecitis, C.D. Conductive CNT-PVDF membrane for capacitive organic fouling reduction. J. Membr. Sci. 2014, 459, 143-156. [CrossRef]

8. Ahmed, F.; Lalia, B.S.; Kochkodan, V.; Hilal, N.; Hashaikeh, R. Electrically conductive polymeric membranes for fouling prevention and detection: A review. Desalination 2016, 391, 1-15. [CrossRef]

9. Formoso, P.; Pantuso, E.; De Filpo, G.; Nicoletta, F.P. Electro-Conductive Membranes for Permeation Enhancement and Fouling Mitigation: A Short Review. Membranes 2017, 7, 39. [CrossRef] [PubMed]

10. Martin, P.M. Handbook of Deposition Technologies for Films and Coatings: Science, Applications and Technology, 3rd ed.; Elsevier: New York, NY, USA, 2010.

11. Zhao, H.B.; Xiong, G.X.; Baron, G.V. Preparation and characterization of palladium-based composite membranes by electroless plating and magnetron sputtering. Catal. Today 2000, 56, 89-96. [CrossRef]

12. Gaedt, L.; Chilcott, T.C.; Chan, M.; Nantawisarakul, T.; Fane, A.G.; Coster, H.G.L. Electrical impedance spectroscopy characterisation of conducting membranes: II. Experimental. J. Membr. Sci. 2002, 195, 169-180. [CrossRef]

13. Chilcott, T.C.; Chan, M.; Gaedt, L.; Nantawisarakul, T.; Fane, A.G.; Coster, H.G.L. Electrical impedance spectroscopy characterisation of conducting membranes: I. Theory. J. Membr. Sci. 2002, 195, 153-167. [CrossRef]

14. Zhang, W.; Wahlgren, M.; Sivik, B. Membrane Characterization by the Contact Angle Technique. Desalination 1989, 72, 263-273. [CrossRef]

15. Nyström, M.; Pihlajamäki, A.; Ehsani, N. Characterization of ultrafiltration membranes by simultaneous streaming potential and flux measurements. J. Membr. Sci. 1994, 87, 245-256. [CrossRef]

16. Luxbacher, T. The Zeta Potential for Solid Surface Analysis: A Practical Guide to Streaming Potential Measurement, 1st ed.; Anton Paar GmbH: Graz, Austria, 2014.

17. Lalia, B.S.; Ahmed, F.E.; Shah, T.; Hilal, N.; Hashaikeh, R. Electrically conductive membranes based on carbon nanostructures for self-cleaning of biofouling. Desalination 2015, 360, 8-12. [CrossRef]

18. Liang, S.; Lu, L.; Meng, F. DOM-mediated membrane retention of fluoroquinolone as revealed by fluorescence quenching properties. Sci. Rep. 2017, 7, 5372. [CrossRef] [PubMed]

19. Green, N.W.; McInnis, D.; Hertkorn, N.; Maurice, P.A.; Perdue, E.M. Perdue, Suwannee River Natural Organic Matter: Isolation of the 2R101N Reference Sample by Reverse Osmosis. Environ. Eng. Sci. 2015, 32, 38-44. [CrossRef]

20. Edzwald, J.K.; Becker, W.C.; Wattier, K.L. Surrogate Parameters for Monitoring Organic Matter and THM Precursors. J. - Am. Water Works Assoc. 1985, 77, 122-132. [CrossRef]

21. Winter, J.; Uhl, W.; Bérubé, P.R. Integrated oxidation membrane filtration process-NOM rejection and membrane fouling. Water Res. 2016, 104, 418-424. [CrossRef] [PubMed]

22. Giesbers, M.; Kleijn, J.M.; Stuart, M.A.C. The electrical double layer on gold probed by electrokinetic and surface force measurements. J. Colloid Interface Sci. 2002, 248, 88-95. [CrossRef] [PubMed] 
23. Dudchenko, A.V.; Rolf, J.; Russell, K.; Duan, W.; Jassby, D. Organic fouling inhibition on electrically conducting carbon nanotube-polyvinyl alcohol composite ultrafiltration membranes. J. Membr. Sci. 2014, 468, 1-10. [CrossRef]

24. Schwartzkopf, M.; Buffet, A.; Körstgens, V.; Metwalli, E.; Schlage, K.; Benecke, G.; Perlich, J.; Rawolle, M.; Rothkirch, A.; Heidmann, B; et al. From atoms to layers: In situ gold cluster growth kinetics during sputter deposition. Nanoscale 2013, 5, 5053-5062. [CrossRef] [PubMed]

25. De Lannoy, C.F.; Jassby, D.; Davis, D.D.; Wiesner, M.R. A highly electrically conductive polymer-multiwalled carbon nanotube nanocomposite membrane. J. Membr. Sci. 2012, 415, 718-724. [CrossRef]

26. Nolte, M.C. Elektrisch leitfähige Umkehrosmosemembranen zur Verminderung des Biofoulings. Ph.D. Thesis, TUHH Universitätsbibliothek, Hamburg, Germany, 3 August 2009.

27. Ronen, A.; Walker, S.L.; Jassby, D. Electroconductive and electroresponsive membranes for water treatment. Rev. Chem. Eng. 2016, 32, 533-550. [CrossRef]

28. Duan, W.; Ronen, A.; Walker, S.; Jassby, D. Polyaniline-Coated Carbon Nanotube Ultrafiltration Membranes: Enhanced Anodic Stability for In Situ Cleaning and Electro-Oxidation Processes. ACS Appl. Mater. Interfaces 2016, 8, 22574-22584. [CrossRef] [PubMed]

29. Ayadi, S.; Jedidi, I.; Rivallin, M.; Gillot, F.; Lacour, S.; Cerneaux, S.; Cretin, M.; Amar, R.B. Elaboration and characterization of new conductive porous graphite membranes for electrochemical advanced oxidation processes. J. Membr. Sci. 2013, 446, 42-49. [CrossRef]

30. Gao, G.; Zhang, Q.; Hao, Z.; Vecitis, C.D. Carbon nanotube membrane stack for flow-through sequential regenerative electro-Fenton. Environ. Sci. Technol. 2015, 49, 2375-2383. [CrossRef] [PubMed]

31. Duan, W.; Chen, G.; Chen, C.; Sanghvi, R.; Iddya, A.; Walker, S.; Liu, H.; Ronen, A.; Jassby, D. Electrochemical removal of hexavalent chromium using electrically conducting carbon nanotube/polymer composite ultrafiltration membranes. J. Membr. Sci. 2017, 531, 160-171. [CrossRef]

32. Yuan, Y.; Kilduff, J.E. Hydrodynamic Modeling of NOM Transport in UF: Effects of Charge Density and Ionic Strength on Effective Size and Sieving. Environ. Sci. Technol. 2009, 43, 5449-5454. [CrossRef] [PubMed]

33. Huotari, H.M.; Huisman, I.H.; Trägårdh, G. Electrically enhanced crossflow membrane filtration of oily waste water using the membrane as a cathode. J. Membr. Sci. 1999, 156, 49-60. [CrossRef]

34. Van den Berg, G.B.; Smolders, C.A. Flux decline in ultrafiltration processes. Desalination 1990, 77, 101-133. [CrossRef]

35. Gorenflo, A. Rückhalt und Fouling von natürlichen organischen Substanzen bei der Nano- und Ultrafiltration. Ph.D. Thesis, Lehrstuhl für Wasserchemie am Engler-Bunte-Inst., Karlsruhe, Germany, 3 February 2003.

36. Staub, C.; Buffle, J.; Haerdi, W. Measurement of complexation properties of metal ions in natural conditions by ultrafiltration: Influence of various factors on the retention of metals and ligands by neutral and negatively charged membranes. Anal. Chem. 1984, 56, 2843-2849. [CrossRef]

37. Ernst, M.; Bismarck, A.; Springer, J.; Jekel, M. Zeta-potential and rejection rates of a polyethersulfone nanofiltration membrane in single salt solutions. J. Membr. Sci. 2000, 165, 251-259. [CrossRef]

38. Stevenson, F.J. Humus Chemistry: Genesis, Composition, Reactions, 2nd ed.; John Wiley \& Sons: Hoboken, NJ, USA, 1994.

39. Barten, D.; Kleijn, J.M.; Duval, J.; Leeuwen, H.V.; Lyklema, J.; Cohen Stuart, M.A. Double Layer of a Gold Electrode Probed by AFM Force Measurements. Langmuir 2003, 19, 1133-1139. [CrossRef] [PubMed]

40. Collins, M.R.; Amy, G.L.; Steelink, C. Molecular weight distribution, carboxylic acidity, and humic substances content of aquatic organic matter: implications for removal during water treatment. Environ. Sci. Technol. 1986, 20, 1028-1032. [CrossRef] [PubMed]

41. Williams, P.M. Membrane Charge Characterization. In Encyclopedia of Membranes; Drioli, E., Giorno, L., Eds.; Springer: Berlin/Heidelberg, Germany, 2015; pp. 1-2.

42. Stumm, W. Aquatic surface chemistry: Chemical processes at the particle-water interface; Wiley: Hoboken, NJ, USA, 1987.

43. Prieve, D.C. Changes in zeta potential caused by a dc electric current for thin double layers. Colloids Surf. A 2004, 250, 67-77. [CrossRef] 
44. Bazant, M.Z.; Kilic, M.S.; Storey, B.D.; Ajdari, A. Towards an understanding of induced-charge electrokinetics at large applied voltages in concentrated solutions. Adv. Colloid Interface Sci. 2009, 152, 48-88. [CrossRef] [PubMed]

45. Duval, J.; Lyklema, J.; Kleijn, J.M.; van Leeuwen, H.P. Amphifunctionally Electrified Interfaces: Coupling of Electronic and Ionic Surface-Charging Processes. Langmuir 2001, 17, 7573-7581. [CrossRef] 